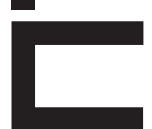

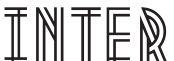

\title{
INTERFACE ENTRE O RELIGIOSO E O POLĹTICO: O GOLPE CIVIL-MILTAR DE 1964 E A IGREJA PRESBITERIANA DO BRASIL
}

Márcio Ananias Vilela ${ }^{1}$

\section{RESUMO}

0 presente artigo versa sobre o comportamento de um relevante segmento protestante, a Igreja Presbiteriana do Brasil, frente ao Golpe civil-militar de 1964. Na produção desta análise, foram analisados diversos documentos institucionais, assim como diferentes jornais impressos, possibilitando mapear algumas relações estabelecidas naquele momento com o Estado, onde aspectos religiosos e políticos se entrecruzam.
A narrativa presente neste artigo visa contribuir para a compreensão do emblemático cenário de embates entre diferentes projetos de sociedade, marcando a construção social da ditadura brasileira pós 1964.

\section{PALAVRAS-CHAVE}

Igreja. Estado. Golpe civil-militar. 


\section{ABSTRACT}

This article deals with the behavior of a material Protestant segment, the Presbyterian Church of Brazil, against the 1964 Civil-Military coup. In the production of this analysis, several institutional documents were analyzed, as well as different print newspapers, allowing map some relationships established at that time with the state, where religious and political aspects intersect. This narrative in this article aims to contribute to the understanding of the emblematic scene of clashes between different projects of society, marking the social construction of the Brazilian dictatorship after 1964.

\section{KEYWORDS}

Church. State.Civil-military Coup.

\section{RESUMEN}

En este trabajo se analiza el comportamiento de un segmento relevante protestante, la Iglesia Presbiteriana de Brasil, frente al golpe de Estado cívico-militar de 1964 la producción En este análisis, se analizaron diversos documentos institucionales, así como varios periódicos, mapa permitiendo algunas relaciones que se establecen ese momento con el estado en el que los aspectos religiosos y políticos se entrelazan. Esta narrativa en este artículo contri- buye a la comprensión de los paisajes emblemáticos de enfrentamientos entre diferentes proyectos de la sociedad, marcando la construcción social de la dictadura brasileña después de 1964.

\section{PALABRAS-CLAVE}

Iglesia. Estado. Golpe de Estado cívico-militar. 


\section{PELA FÉ E SALVAÇ̃̃O POLÍTICA: EMBATES SOBRE OS RUMOS DA DEMOCRACIA BRASILEIRA NOS IDOS DE 1964}

As ações militares de março/abril de 1964 foram capazes de mobilizar importantes e diversos segmentos sociais, seja em ações de apoio ou de repúdio. No que tange aos protestantes, o teólogo norte-americano Alexander Reily argumentou que sua grande maioria estava entre aqueles que recepcionaram positivamente o novo governo. Assim, houve:

\begin{abstract}
[...] um alto grau de aceitação da intervenção militar pelos protestantes, a princípio pelo medo que João Goulart estivesse conduzindo o país para um caos socialista e possivelmente à guerra civil. Nesse caso o novo regime representou a salvação política da pátria. Medo da esquerda e simpatia pela direita parece refletir fielmente a mentalidade protestante majoritária. (REILY, 2003, p. 309).
\end{abstract}

Um contingente considerável de protestantes apresentava naquele momento a conviç̧ão de que o Brasil pudesse ser dominado por comunistas ateus. Diante do quadro bastante amplo de apoio protestante ao Golpe de 1964, interessa-nos analisar como esse apoio se materializou em discursos e práticas.

Segundo o ponto de vista de um dos poucos estudiosos sobre a relação da Igreja Presbiteriana do Brasil/ IPB² com os militares, João Dias de Araújo (2010, p. 95):

Entre as igrejas evangélicas do Brasil, a Presbiteriana foi a mais envolvida e a mais comprometida com a revolução de 1964 por causa das ligações dessa Igreja com a classe média e por causa do prestígio político que ela gozava nos meios políticos e militar.

\footnotetext{
2. Esse grupo religioso vai sendo formado quando a Igreja Presbiteriana norte-americana, a partir de meados do século XIX, passou a enviar sistematicamente missionários ao Brasil com o objetivo bem definido de propagar a fé protestante. Em agosto de 1859 chegou ao Brasil o jovem missionário e Pastor Ashbel Green Simonton, proveniente de igrejas presbiterianas do Norte dos EUA, enviado pela Junta de Missões Estrangeiras, localizada em Nova York; esta, portanto, tem sido a data propagada pela Igreja Presbiteriana do Brasil para fins comemorativos, como marco inicial do presbiterianismo em território nacional.
}

Para estudar este envolvimento, privilegiamos analisar algumas matérias e editorias do Jornal Brasil Presbiteriano. Analisar este periódico nos permite entender certas particularidades da Igreja Presbiteriana frente ao Golpe civil-militar de 1964. Especificidades que a diferem de instituições religiosas como a Igreja Metodista, cuja cúpula praticamente não se manifestava em relação ao Golpe na imprensa oficial, o jornal Expositor Cristão (ALMEIDA, 2009). Neste sentido, na edição datada da $2^{a}$ quinzena de março daquele ano mas que circulou apenas em abril, tendo ainda como redator o pastor Domício Pereira Matos - foi publicado um editorial apresentando posição sobre as ações militares que depuseram o presidente João Goulart.

\footnotetext{
Transformou-se completamente a face da Nação. 0 alto comando militar assumiu as rédeas do país, deu- lhe certos aspectos constitucionais [...] revestiu de poderes especiais e está fazendo a "limpeza" para que os comunistas, agitadores e peculatários fiquem de fora, e por muito tempo, sem os direitos políticos que thes eram assegurados. [...] Com a mudança da fisionomia política da Nação, muitos mudaram a sua própria fisionomia. Há os que estão por cima e, entre eles, alguns maus brasileiros que deveriam ficar por baixo. [...] Nós não precisamos mudar. Graças a Deus estamos tranqüilos e prontos a recomeçar a nossa pregação e a insistir nos pontos que temos ferido a respeito do Brasil e da necessidade de reformas estruturais para que haja melhores condições de vida para o nosso povo. [...] Graças a Deus, estão sendo banidos da Nação os agitadores extremados e, assim, não haverá mais perigo de os reacionários da direita, com a finalidade de nos combaterem, insistirem na confusão que gostam de fazer - todo reformista, todo pregador da justiça social, todo propugnador por um Brasil social e economicamente equilibrado é comunista. [...] Porque a situação política do Brasil mudou não vamos deixar de dizer que [...] camponeses estão sendo escravizados por situação agrária que não lhes permite o mínimo de conforto e bem estar. [...] O Cristianismo não pode ficar indiferente ao quadro social do Brasil. Precisa erguer a sua voz para dizer o que está aconte-
} 
cendo e estender suas mãos para ajudar o Governo a resolver os grandes e graves problemas 3 .

O editorial demarcava um lugar político ao apresentar a Igreja como porta-voz das reformas estruturais do Brasil junto ao novo governo. Igreja e Estado deveriam caminhar na mesma direção e sanar o grave quadro social que se fazia presente. A mudança no campo político com a presença dos militares no governo após março de 1964, não acarretaria, a princípio, prejuízos na maneira de agir e pensar da Igreja em relação aos problemas sociais do país. Pelo contrário, a Igreja deveria tornar mais sólida sua posição em defesa das reformas estruturais, com a vantagem de não ser, a partir de então, confundida ou nomeada como comunista.

Era um discurso que também propunha diferenciação entre aqueles considerados oportunistas, ou seja, apoiadores das mudanças sociais de última hora, e os tidos como coerentes com a defesa das reformas sociais no Brasil desde antes da ocorrência do Golpe. Sobre este aspecto, Thomas Skidmore (1982, p. 375) afirmou que o presidente Castelo Branco “ponderava que a revolução tinha sido feita para assegurar desenvolvimento econômico e justiça social para todos". Na imprensa, este foi um discurso muito difundido. No estado de Pernambuco, em 1964 - sobretudo nos primeiros meses após o Golpe - o Jornal do Commercio em Pernambuco partilhava desta visão, fazendo circular um discurso produzido por setores militares que pregavam a necessidade de realização das reformas sociais.

Analisando o referido editorial, podemos inferir que alguns pastores e líderes leigos apresentavam-se comprometidos com as reformas e até mesmo com o governo de João Goulart e sintonizados com o que ficou conhecido como Evangelho Social ${ }^{4}$, apoiaram, pelo menos neste primeiro momento, as ações militares de março/abril de 1964. Inclusive, podemos evidenciar

3. REAFIRMAÇÃO de Princípios. Jornal Brasil Presbiteriano, n. 06, p. 03, mar 1964. Grifo mantido do original.

4. O termo Evangelho Social surge nos EUA no início do século XX. Trata-se de uma reformulação teológica onde o papel da Igreja frente as questões social e política foi profundamente problematizado. que chegavam a defender as cassações e a repressão, em referência, provavelmente, ao Al-1. Medidas de exceções que, segundo Moniz Bandeira (2010, p. 348349) assegurava aos militares a possibilidade de cassar mandatos e suspender por até dez anos os "direitos políticos de senadores, deputados, vereadores, justamente os mais votados do Brasil, tudo em nome da democracia representativa, ocidental e cristã".

Esta aprovação e comprometimento com o Golpe não se restringiu à Igreja Presbiteriana do Brasil, mas perpassou outros segmentos da sociedade, como amplos setores da Igreja Católica Romana; significativo exemplo disso foi dom Hélder Câmara, arcebispo de Olinda e Recife que também manteve, durante algum tempo, posição de apoio aos militares.

Sobre a posição oficial da Igreja Católica em relação ao Golpe civil-militar de 1964, Scott Mainwaring analisa que a Conferência Nacional dos Bispos do Brasil (CNBB), após haver apoiado o projeto de reformas sociais do governo de João Goulart, acabou por fortalecer a oposição e defender o Golpe. Porém, o autor problematizou essa posição analisando o manifesto da CNBB, de julho de 1964, intitulado Declaração da CNBB sobre a Situação Nacional que, segundo o próprio Scott, apresentou-se como contraditório por expressar certas críticas ao Regime, expondo a exis tência de divergências. No entanto, sobressaiu neste documento da CNBB um notável apoio aos militares:

\footnotetext{
Atendendo à geral e angustiosa expectativa do Povo Brasileiro, que via a marcha acelerada do comunismo para a conquista do Poder, as Forças Armadas acudiram em tempo, e evitaram que se consumasse a implantação do regime bolchevista em nossa Terra. [...] Logo após o movimento vitorioso da Revolução, verificou-se uma sensação de alívio e de esperança, sobretudo porque, em face do clima de insegurança e quase desespero em que se encontravam as diferentes classes ou grupos sociais, a Proteção Divina se fez sentir de maneira sensível e insofismável. [...] Ao rendermos graças a Deus, que atendeu as orações de milhões de brasileiros e nos livrou do perigo comunista, agradecemos aos militares que se levantaram em nome dos supremos interesses da Nação. (MAINWARING, 2004, p. 102).
} 
A aprovação e apoio ao governo começavam efetivamente a ser volumosos na imprensa presbiteriana, a partir do mês de maio. Grupo que se torna dominante na Igreja Presbiteriana do Brasil e no comando do jornal, implementando outra orientação religiosa e política ao jornal, em grande medida diferente da que existia, onde predominava a visão de que a igreja deveria ter uma ativa participação política e social frente às reformas que o país necessitava. São matérias elogiosas à nova situação política do país: exemplo dessa perspectiva foi a divulgação de uma mensagem de congratulações ao governo, intitulada Representação ao Sr. Presidente da República. A matéria, dirigida ao Presidente Marechal Castelo Branco, foi apresentada na Câmara dos Deputados pelo parlamentar do estado de São Paulo, Lauro Monteiro da Cruz, solicitando orações dos presbiterianos ao novo governo:

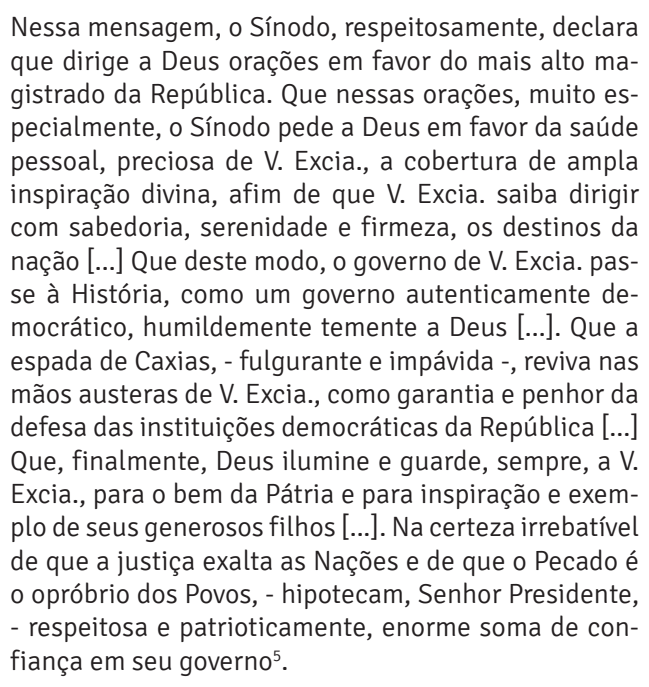

A mensagem foi assinada pelo Pastor Gutenberg de Campos, Secretário responsável pelas atividades cívico-sociais do Sínodo Oeste do Brasil, que abrangia

5. REPRESENTAÇÃO ao Sr. Presidente da República. Jornal Brasil Presbiteriano, n. 8, p. 1, maio 1964. É importante mencionar que este número circula, tardiamente, no mês de maio devido a alterações como a interrupção do jornal e mudanças em sua direção efetivadas em final de abril. apenas parte do estado de São Paulo ${ }^{6}$. A mensagem incorpora uma homogeneidade supostamente existente para toda a Igreja Presbiteriana, chegando mesmo a se referir em termos nacionais, expressando qual deveria ser a vontade do Brasil e da Igreja naquela hora. Ao mesmo tempo, defendia-se as instituições democráticas nacionais, legitimando a utilização da violência por parte do Marechal Presidente Humberto Castelo Branco. Sua imagem política era associada ao Duque de Caxias, personagem histórico nacionalmente reconhecido naquele momento como um pacificador por meio das suas ações durante a Guerra do Paraguai.

Com o uso político da fé e posicionamento político da Igreja Presbiteriana do Brasil, almejava-se a salvação democrática como um projeto de pacificação dos embates existentes no Brasil nos idos de 1964, reconhecendo-se inclusive o autoritarismo como prática necessária na defesa da nação e legalidade democrática contra a possível subversão comunista.

\section{A "REVOLUÇÃO" COMO PROVIDÊNCIA DIVINA}

Ainda no mês de maio, o Pastor Oscar Chaves, que naquele momento trabalhava e residia na cidade de Santo André (SP), publicou no jornal Brasil Presbiteriano uma matéria em que afirmava:

\begin{abstract}
Todos os verdadeiros cristãos se regozijaram e estão regozijando com os resultados da gloriosa revolução de março-abril: o expurgo dos comunistas e seus simpatizantes, da administração do nosso querido Brasil. A Providência de Deus se fez sentir na hora certa, quando muitos fiéis, já ansiosos e temerosos, pensavam que a nação teria de ser flagelada pela horda dos anarquistas e materialistas - Deus agiu na hora certa, repetimos usando a coragem e o patriotismo das Forças Armadas e de civis?.
\end{abstract}

6. Neste momento o estado de São Paulo contava com mais um Sínodo, isso porque a referida unidade federativa dispunha de aproximadamente 263 templos religiosos. Tratava-se de um número significativo se compararmos com o da Região Nordeste, que neste mesmo período atingia quantitativo total estimado de 331 templos. Estes são dados estimados referentes ao ano 1967, extraídos da Estatística do Culto Protestante do Brasil 1967, do Serviço de Estatística Demografia, Moral e Política, órgão ligado ao Ministério da Justiça. 7. Jornal Brasil Presbiteriano, n.8, p.7, maio 1964. 
Há neste fragmento a preocupação do pastor em não apresentar qualquer distinção doutrinária. Pelo contrário, constrói uma imagem em que todos eram cristãos e estavam felizes com os acontecimentos recentes e seus resultados políticos. Essas ações, inclusive o autoritarismo do novo regime, eram entendidas como necessárias diante do avanço do Comunismo e radicalização das esquerdas que ameaçavam dominar e administrar o Brasil. Ressaltava-se a relevante coragem de setores militares e civis que ao agirem unidos em torno de um bem maior - a salvação democrática - também agiam sob a determinação de Deus.

As ações militares não foram apresentadas como um Golpe e sim como uma revolução capaz de reestabelecer a ordem e levar o País à normalidade política e social. Entendemos, portanto, que para este setor da Igreja Presbiteriana do Brasil, esta irresistibilidade $^{8}$ da revolução não ocorreu por uma vontade em si, como ação que se assemelhe aos movimentos cíclicos dos astros, mas que se trata de um movimento fruto da "Providência de Deus" e, como tal, deve ser algo imutável.

Podemos aferir que aquele momento foi apresentado como o cumprimento da etapa desconhecida e incompreendida por muitos brasileiros, mas necessária e previsível aos desígnios divinos em direção ao juízo final. Representava-se, assim, uma concepção temporal linear e teleológica dos episódios políticos, pois aquela tinha sido a hora de Deus. E sendo a revolução de 1964 uma ação estabelecida por Deus, ela foi construída pelo periódico Brasil Presbiteriano como um movimento glorioso. Muito provavelmente incorporando como referência positiva ou modelo a ser seguido por todos os países cristãos, a Revolução Gloriosa de 1688, na Inglaterra, quando foi "possível depor uma odiosa dinastia sem derramamento de sangue" (KOSELLECK, 2006, p. 68).

8. 0 termo irresistibilidade foi empregado por Hannah Arendt para pensar período revolucionário na França no final do século XVIII, mais precisamente a Revolução Francesa (ARENDT, 2011, p. 78-81).
É importante ressaltar que a imagem do Golpe como ação cristã era sistematicamente reforçada naquele periódico por seu caráter pacífico de que não haveriam ocorrido embates sangrentos, em detrimento da violência e ameaças provocadas pelos comunistas durante um governo que compactuava com a corrupção e com o desrespeito às instituições democráticas. Tratava-se de um discurso construído pela Igreja para legitimar o Golpe como ação derivada da providência divina, enquanto a posição política anterior a 1964 passou a ser vista como destituída de qualquer respaldo divino.

Na edição de junho de 1964, o jornal publicou extensa matéria cujos argumentos reforçam a confiança da Igreja no governo militar, além de projetar qual deveria ser o papel da Igreja Presbiteriana do Brasil na nova ordem política. Ou seja, o jornal continuava convocando e proclamando o apoio dos presbiterianos e dos cristãos às Forças Armadas e ao Presidente:

Tudo indica, pois, que as forças armadas intervieram com senso de oportunidade [...]. Cremos que os presbiterianos, seja qual for o partido, devem a si mesmo, a Cristo e a Nação uma atitude positiva de participação nas tarefas [...] que aguardam o país [...]. O presidente da República tem se revelado um cidadão sereno, judicioso, bem intencionado [...] Merece, com seu governo, o apoio dos cristãos ${ }^{9}$.

A matéria esclareceu que a intervenção militar de março de 1964 foi traçada respeitando um senso de oportunidade. Tratava-se, portanto, de ação legítima, referendada. Circunstâncias perante as quais não só os presbiterianos mais todos os cristãos, sem distinção de credo, deveriam assumir posição de intenso apoio e lealdade para com o novo governo, independentes de questões partidárias. Este era o momento de união, de participação de todos no novo caminho. Somava-se a isso o fato de que o Brasil se encontrava chefiado por um homem imbuído de qualidades fundamentais, sendo descrito não apenas como militar, um Marechal, mas também como autêntico cidadão brasileiro.

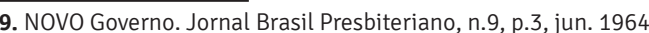


Analisando os jornais de outras igrejas protestantes a respeito do Golpe de 1964, como o periódico da Igreja Batista, há uma considerável sintonia com a política editorial do jornal da IPB. Em abril daquele ano, foi publicado no $O$ Jornal Batista, um artigo intitulado Novo Governo, expressando o que seria o pensamento do povo brasileiro e o pensamento daquela instituição. Assim que:

\begin{abstract}
Nosso novo presidente empossado em cerimônia solene no dia 15 de abril, foi, como chefe do Estado-Maior do exército, um dos líderes da revolução vitoriosa, que em dois dias empolgou o Brasil inteiro, sem encontrar nenhuma resistência a sua indicação pelos mentores civis e militares da revolução, foi unânime e o Congresso nada mais fez que chancelar essa escolha ${ }^{10}$.
\end{abstract}

Segundo a historiadora Elizete Silva, houve, de fato, por parte dos batistas, um apoio imediato às ações militares (SILVA, 2009, p. 35). Essa posição era anunciada em artigo intitulado Responsabilidade dos crentes nesta hora, que circulou no dia 12 abril:

Os acontecimentos militares de 31 de março e $1^{\circ}$ de abril que culminaram com o afastamento do Presidente da República vieram, inegavelmente, desafogar a nação [...]. o presidente que vinha fazendo um jogo extremamente perigoso foi afastado. A democracia já não está mais ameaçada. A vontade do povo foi entendida e respeitada [... ${ }^{11}$.

Observa-se, em relação ao apoio ao governo militar, que $O$ Jornal Batista refere-se a uma homogeneidade institucional, além de justificar a posse do Marechal Humberto Castelo Branco em clima de consenso entre os militares e civis envolvidos com o Golpe. As ações militares foram apresentadas como uma revolução, reforçando ainda mais o apoio a essas ações. Em outros termos, 0 Jornal Batista construiu um discurso no qual o Golpe reestabeleceu a democracia e expressou a vontade do povo. Tal entendimento parece mesmo ter sido bastante comum entre setores preponderantes do protestantismo nacional, como a Igreja

10. NOVO governo. O Jornal Batista, p.3, 26 abr. 1964.

11. RESPONSABILIDADE dos crentes nesta hora. O Jornal Batista, p.3, 12 abr. 1964.
Batista e a IPB, que naquele momento representavam as duas maiores instituições protestantes do país ${ }^{12}$.

Em Pernambuco, o apoio aos militares por parte da Igreja Presbiteriana do Brasil foi publicamente divulgado já em 5 de abril, momento em que o Sínodo de Pernambuco utiliza-se de um dos maiores jornais em circulação no estado, o Jornal do Commercio. Neste momento o Sínodo de Pernambuco tem sob sua jurisdição, aproximadamente 100 igrejas presbiterianas. Assim, orienta tais igrejas para que fosse realizado um Culto de Ação de Graças.

\begin{abstract}
A Secretaria de Educação Religiosa do Sínodo de Pernambuco, jurisdicionando as igrejas regionais, está recomendando que seja realizado culto de ação de graça pela preservação das garantias nacionais que, em hora oportuna, o valoroso soldado brasileiro soube defende-las. Recomenda ainda orações pelas nossas autoridades - civis e militares que, nesta - nova fase do destino de nosso querido Brasil, sejam inspiradas em toda a justiça e amor para todas as classes sociais principalmente os mais pobres e humildes ${ }^{13}$.
\end{abstract}

O comunicado destacava dois significativos atos religiosos a serem realizados: o culto em ação de graças e orações em favor do novo governo, ambos com a função primordial de anunciar o Golpe como instituído por Deus, portanto, inquestionável; além de tornar pública a posição da IPB em Pernambuco.

O culto de ação de graças é um momento quando toda a comunidade religiosa de determinada Igreja é convidada a prestar agradecimentos a Deus por uma vitória alcançada a um dos seus membros ou uma graça que tenha atingido a coletividade. Esta prática dos cultos de ação de graças parece mesmo haver sido bastante disseminada no período, como relembrou o professor Zwinglio Mota Dias, que em 1964 era um recém-pastor presbiteriano no estado de Minas Gerais. Segundo o Pr. Dias, "as Igrejas faziam muitos cultos

12. Sobre o apoio da Igreja Batista ao Golpe de 1964 na Bahia, ver Almeida (2010).

13. CULTO de ação de graça dos presbiterianos. Jornal do Commercio, Recife, p.48, 5 abr. 1964. 
de gratidão a Deus pelo Golpe. Pedindo a Deus a benção para um novo Brasil que estava nascendo graças aos militares"14.

É possível que inúmeras igrejas tenham de fato seguido as orientações da cúpula estadual, porém pesquisar a recepção de tais recomendações revelou-se difícil tendo em vista as dificuldades em acessar os documentos, sobretudo porque as instituições não demonstram interesse em sua divulgação, vindo a defini-los como de uso interno, ficando tais documentações sob a guarda dos Conselhos das Igrejas.

No Boletim Dominical ${ }^{15}$ da Igreja Presbiteriana da Boa Vista, localizada em uma área central na cidade do Recife, no primeiro domingo após o Golpe civil-militar, não localizamos quaisquer referências àquele acontecimento. Uma possibilidade é que o Boletim já estivesse confeccionado pela gráfica, não havendo como inserir qualquer comentário ou nota. Ou ainda, que os líderes da Igreja preferiram aguardar um pouco mais para terem segurança que os golpistas tinham o controle do País. No entanto, no domingo seguinte, 12 de abril, circulou em sua primeira página um editorial sob o título, "Oremos pela Pátria, conclamando seus crentes a orar pela Pátria a fim de que Deus oriente os que a dirigem na solução de seus angustiosos problemas [...]. Compareça à reunião de oração, todos os domingos, antes da Escola Dominical, no terceiro pavimento"16.

Em 19 de abril, foi publicado, também, em primeira página outro informe se utilizando do mesmo título Oremos pela Pátria, o Boletim esclarece que, “a Bíblia nos manda orar pelas autoridades. Aqui é casa de oração. Oremos, irmãos, oremos pela Pátria e Deus, que rege os destinos das nações, guiará nossos destinos" ${ }^{17}$. Os infor-

14. Zwinglio Mota Dias foi entrevistado na cidade do Rio de Janeiro/RJ, em dezembro de 2011, pelo pesquisador Márcio Vilela. Zwinglio é teólogo, ex-pastor presbiteriano e professor da Universidade Federal de Juiz de Fora.

15. Os Boletins seguiam um padrão, eram publicações de formato retangular contendo várias páginas com informações breves, distribuídos sempre aos domingos pelas manhãs para todos os membros e frequentadores em geral. 16. Boletim da Igreja Presbiteriana da Boa Vista, Ano XII - Recife, domingo 12 de abril de $1964, n^{\circ} 565$. Arquivo Interno.

17. Boletim da Igreja Presbiteriana da Boa Vista, Ano XII - Recife, domingo, mes, a exemplo do ocorrente no jornal Brasil Presbiteriano, reforçam a posição de legitimidade em relação aos militares. Aprovação que deveria ser confirmada e aceita por todos, com orações e preces pelo novo governo e pelo Brasil, como determina a própria Bíblia.

Podemos pensar que esta posição anunciada nos Boletins também estivesse relacionada a indagações que o Conselho da Igreja ${ }^{18}$ recebia de membros preocupados com os recentes acontecimentos no país. Analisando as Atas do Conselho da Igreja de 20 de abril de 1964 deparamo-nos com o seguinte registro: “Recebe-se uma carta do membro desta Igreja [...] solicitando do Conselho sua definição sobre a atitude da Igreja em face do movimento revolucionário brasileiro [...]"19. Diante desta solicitação, o Conselho reporta-se “ao irmão agradecendo-lhe o interesse pela segurança ideológica da Igreja, pedindo sua colaboração no sentido de apontar membros da Igreja porventura agitadores para admoestá-los à luz da Bíblia"20.

Com esta posição, o Conselho estimula no interior da Igreja uma política de vigilância e de denuncismo, onde todos eram responsáveis pelo cumprimento da ordem. Mas, levando-se em consideração a preocupação externada pelo remetente e a posição do Conselho da Igreja, havia ali pessoas com pensamentos discordantes quanto à legitimidade do Golpe civil-militar, daí a vontade de saber qual deveria ser a posição daquela Igreja. Nomeados de agitadores - e neste caso, podemos supor que pudessem mesmo haver sido descritos como comunistas, pois essa era identificação bastante comum naquele momento - estes deveriam ser identificados com a ajuda do próprio emissário da carta, e posteriormente admoestados. Vemos, então

19 de abril de $1964, n^{\circ} 566$. Este mesmo comunicado foi publicado no boletim do domingo 10 de maio de $1964, \mathrm{n}^{\circ} 569$. Arquivo Interno.

18. 0 Conselho de dada Igreja é formado pelo pastor, que é quem preside, e os presbíteros eleitos pela membresia para mandatos regulares (esses presbíteros são, em sua maioria, pessoas consideradas experientes naquela Igreja). São estes Conselhos que administram as igrejas locais.

19. Ata da Igreja Presbiteriana da Boa Vista, $n^{\circ} 885,20 / 04 / 64$, p. $24 /$ b. Livro VII, $\mathrm{n}^{\circ} 876$ a 923 . Arquivo Interno.

20. Ata da Igreja Presbiteriana da Boa Vista, $n^{\circ} 885$, 20/04/64, pp. 24/b-25/a. Livro VII, n876 a 923. Arquivo Interno. 
que o próprio Conselho da Igreja estimula uma política de "deduragem".

Além da documentação interna das igrejas, que tratava da convocação e realização de orações e cultos em ação de graças em apoio e em defesa do Golpe, circulou no jornal Diario de Pernambuco, no dia 7 de abril - portanto, antes mesmo da realização da Marcha da Família acontecida na cidade do Recife, aos 9 de abril - um manifesto de apoio e de júbilo em face da atuação das Forças Armadas brasileiras elaborado pela Igreja Presbiteriana Fundamentalista ${ }^{21}$. 0 manifesto foi uma saudação aos militares como aqueles que, pela misericórdia de Deus e na hora apropriada, salvaram o Brasil da praga maligna que era o Comunismo, sendo concluído com uma convocação a todos os evangélicos da cidade para orar, louvar e agradecer a Deus pelo movimento militar em um culto solene também de ação de graças:

Convidamos daqui, todos os membros das Igrejas Presbiteriana Fundamentalista, todos os batistas fundamentalistas, todos os pentecostais fundamentalistas e finalmente todos os realmente evangélicos, sejam presbiterianos, congregacionais ou batistas, para a grande concentração de Ação de Graças que se realizará no templo da Igreja Presbiteriana do Recife, na próxima terça-feira, 7 de abril, às 20 horas $^{22}$.

Neste sentido, a Igreja Presbiteriana Fundamentalista ${ }^{23}$ e a Igreja Batista manifestaram publicamente seu apoio ao Golpe civil-militar de 1964; entretanto, no que diz respeito à IPB, havia setores que revelaram prudência frente aos acontecimentos de março/abril de 1964: referimo-nos às unidades de ensino teológico, como o Seminário Presbiteriano do Norte/SPN.

21. Trata-se de divisão ocorrida na IPB na década de 1950, em Pernambuco. A Igreja Presbiteriana Fundamentalista mantinha como líder o pastor presbiteriano Israel Gueiros.

22. PRESBITERIANOS promoverão concentração de júbilo. Jornal Diario de Pernambuco, Recife, 7 abr. 1964. Segundo Caderno, p.4.

23. Trata-se de divisão ocorrida na IPB na década de 1950, em Pernambuco. A Igreja Presbiteriana Fundamentalista mantinha como líder o pastor presbiteriano Israel Gueiros.

\section{A RACIONALIZAÇ̃̃o DA FÉ NA REVOLUÇÃo}

Em 10 de abril de 1964, em Assembleia do Diretório Acadêmico que contou com a participação tanto dos seminaristas como do Reitor - o norte-americano Paul Everest Pierson - e professores representantes dos docentes, foi redigida a seguinte Ata em relação aos recentes acontecimentos políticos do país:

\begin{abstract}
O Reitor Paul Pierson [...] pediu orações pelo Seminário e pela Pátria, acrescentando que devemos manter uma posição equilibrada e cristã. A professora [ilegível] Pester, em nome das esposas dos professores, reiterou o seu apoio às palavras do Reitor ${ }^{24}$.
\end{abstract}

No mês de maio, em uma reunião extraordinária da Congregação dos Professores do Seminário - órgão composto de professores, Reitor e Deão - foi proferido um discurso que procurou respaldar o golpe militar. Entre alguns pontos presentes, destaca-se que era necessário “acatar e apoiar as autoridades públicas constituídas e colaborar com elas nos compromissos assumidos com a nação [...]"25.

Em uma posterior Assembleia dos Estudantes, também, houve a preocupação por parte do Reitor em solicitar orações em prol do país, e que os seminaristas - em grande maioria residentes na instituição - mantivessem uma posição de prudência cristã em relação ao governo militar. Para ele, era preciso que os seminaristas aceitassem as autoridades civis, pois uma vez instituídas por Deus seriam inquestionáveis. Ao mesmo tempo alerta aos estudantes, que exerciam alguma atividade política, sobre os perigos daquele momento. 0 Reitor sabia que alguns professores e alunos do SPN interagiam consideravelmente com toda uma discussão - apresentada anteriormente - em torno de um Evangelho que considerava a pobreza como questão social e política, como era o caso do professor João Dias de

24. Livro de Ata do Diretório Acadêmico George Edward Henderlight, $n^{\circ} 49$, 10/04/64. Arquivo Histórico do Seminário Presbiteriano na cidade do Recife. 25. Livro de Atas da Congregação dos Professores do Seminário Presbiteriano do Norte, n¹80, 20 e 27/05/64, p. 165. Arquivo Histórico do Seminário Presbiteriano na cidade do Recife. 
Araújo, um dos maiores propagadores e defensores do Pronunciamento Social da Igreja e participante da Conferência do Nordeste em 1962.

Não sabemos até que ponto os alunos corresponderam ao pedido do Reitor Paul Everest Pierson, mas neste primeiro instante, após o Golpe de 1964, não foram localizados documentos que registrassem críticas aos militares por parte dos seminaristas e nem mesmo dos professores do SPN. Algo um pouco diferente havia ocorrido em outra unidade de ensino teológico, no Seminário Presbiteriano do Sul/SPS, localizado na cidade de Campinas, estado de São Paulo; onde o Centro Acadêmico Oito de Setembro (CAOS) enviou à Comissão Executiva do Supremo Concílio - reunida em Brasília no início de 1965 - um relatório de suas atividades referentes ao ano anterior. Em relação ao Golpe civil-militar, o relatório - assinado pelo Presidente do CAOS, o seminarista Elias Abrahão - externava a seguinte posição:

Um outro fato que deve ser aqui mencionado, mais para evitar falsas interpretações do que informar, é o ocorrido em nosso Seminário logo após o movimento do dia 31 de março, ocasião em que o nosso Centro Acadêmico esteve reunido em sessão permanente. $A$ finalidade desta sessão era a de manter os colegas em contato com as atividades estudantis, não querendo isto significar uma subserviência pacífica aos interesses da organização estudantil nacional (UNE). Houve, na ocasião, um pedido à congregação do SPS, para suspensão das aulas, enquanto durasse a crise polí tico-militar, pedido que não foi atendido. Não houve por parte do corpo discente, nenhuma manifestação, ainda que alegássemos não ser produtivo um estudo naquelas condições ${ }^{26}$.

A reação dos alunos do SPS - pelos menos daqueles ligados ao Centro Acadêmico - ao Golpe civil-militar, seja por meio de sessões permanentes ou por seus contatos com a UNE, não levou à suspensão ou alteração das atividades na instituição de ensino. Ex-

26. Relatório do Presidente do CAOS, referente ao ano de 1964. Pasta referente à Reunião Ordinária da Comissão Executiva do Supremo Concílio da Igreja Presbiteriana do Brasil, realizada na cidade de Brasília, no início de 1965. Arquivo Histórico Presbiteriano na cidade de São Paulo. cetuando-se esta posição por parte do corpo discente, a Congregação dos Professores e a própria direção do SPS não externaram nenhum tipo de comunicado - o qual tivéssemos acesso - condenando ou apoiando as ações militares de março de 1964.

\section{CONSIDERAÇÕES FINAIS}

É possível inferir que houve entre alguns setores da IPB uma manifestação de prudência e que poucas foram as vozes e manifestações contrárias às ações dos militares neste primeiro instante, mas prevaleceu uma correspondência de mentalidades e expectativas que circulavam no cenário sociopolítico e religioso, em relação ao Golpe de 1964.

A Igreja Presbiteriana do Brasil constituía-se, assim, em considerável força de legitimação, tendo em vista a sua capacidade para conferir ao Regime "uma aparência de inevitabilidade, firmeza e durabilidade análogas a essas qualidades tais como se atribuem aos próprios deuses" (BERGER, 1985, p. 49).

Em outros termos, e avançado um pouco mais nos limites dessa problemática, podemos afirmar que a Igreja passou a estruturar/compor uma rede de apoio ao governo, cujo discurso, ressaltava o papel da Igreja diante da nova configuração política do Brasil, a saber: o combate ao Comunismo e o caráter divino do Golpe civil-militar.

\section{REFERÊNCIAS}

ALMEIDA, Luciane Silva de. 0 comunismo é o ópio do povo: representações dos batistas sobre o comunismo, o ecumenismo e o governo militar na Bahia (1963-1975). 2010. Dissertação (Mestrado em História) - Departamento de Ciências Humanas e Filosofia, Universidade Estadual de Feira de Santana, 2010. ALMEIDA, Vasni de. Os Metodistas e o Golpe Militar de 1964. Estudos de Religião, v.23, n.37, p.54-68, jul./ 
dez. 2009

ARAÚJO, João Dias de. Inquisição sem fogueiras: a história da igreja presbiteriana do Brasil. São Paulo: Fonte, 2010.

ARENDT, Hannah. Sobre a revolução. São Paulo: Companhia das Letras, 2011.

BERGER, Peter. 0 dossel sagrado: elementos para uma teoria sociológica da religião. São Paulo: Paulinas, 1985.

KOSSELLECK, Reinhart. Futuro passado: contribuição à semântica dos tempos históricos. Rio de Janeiro: Contraponto/PUC-Rio, 2006.

MAINWARING, Scott. A Igreja Católica e a política no Brasil (1916-1985). São Paulo: Brasiliense, 2004.

MONIZ BANDEIRA, Luiz Alberto. 0 governo João Goulart: as lutas sociais no Brasil, 1961-1964. São Paulo:
UNESP, 2010.

PIERSON, Paul. A younger church in a search of maturity: presbyterianism in Brazil from 1910 to 1959. San Antonio: Trinity University Press, 1974.

REILY, Alexander Durkan. História documental do protestantismo no Brasil. São Paulo: AEST, 2003.

SILVA, Elizete da. Protestantes e o governo militar: convergências e divergências. In: ZACHARIADHES, Grimaldo Carneiro (Org.); IVO, Alex de Souza... et al. Ditadura Militar na Bahia: novos objetos, novos horizontes. Salvador: EDUFBA, 2009.

SKIDMORE, Thomas E. Brasil: de Getúlio a Castelo Branco, 1930-1964. Rio de Janeiro: Paz e Terra, 1982. 